\title{
Photodegradation test of asphalt binder using pressed thin film samples
}

\author{
Katsuyuki Yamaguchi, Iwao Sasaki, and Seishi Meiarashi
}

\begin{abstract}
The photodegradation behavior of a straight asphalt was investigated using a new method "photodegradation test of asphalt binder using pressed thin film samples". Although the photodegradation caused by outdoor exposure is limited to the near surface, the results confirmed that the degree of degradation during 1 to 2 months is more severe than that by the pressure aging vessel (PAV) test, which is designed to simulate the degradation that will occur in the asphalt pavement over 5 to 10 service years.
\end{abstract}

Key words: asphalt binder, aging, photodegradation, thin film, DSR, FTIR.

Résumé : Le comportement à la photodégradation d'un asphalte sans additif a été étudié en utilisant une nouvelle méthode, « essai de photodégradation d'échantillons de minces couches pressées de liant routier ». Bien que la photodégradation engendrée par l'exposition aux éléments soit peu profonde, les résultats ont confirmé que le niveau de dégradation durant 1 à 2 mois est plus élevé que celui indiqué par l'essai de vieillissement PAV (pressure aging vessel) qui est conçu pour simuler la dégradation du revêtement en asphalte durant une période de 5 à 10 ans.

Mots clés : liant routier, vieillissement, photodégradation, mince couche, rhéomètre de cisaillement dynamique (« dynamic shear rheometer : DSR »), FTIR.

[Traduit par la Rédaction]

\section{Introduction}

It is known that asphalt materials lose their viscosity and are prone to gradual degradation during storage, paving construction, and in-service when they are exposed to heat, air, and ultraviolet (UV) radiation. Various accelerated aging tests have been developed and established to effectively simulate the actual degradation. Asphalt binders need to be evaluated not only on the initial performance of the products but also on the medium and long-term performance. For example, the thin film oven (TFO) test or the rolling TFO test is

Received 6 September 2004. Revision accepted 21 June 2005. Published on the NRC Research Press Web site at http://cjce.nrc.ca on 18 October 2005.

K. Yamaguchi. ${ }^{1}$ Chita Research Institute, Tokai Carbon Co., Ltd., 5-1 Taketoyo, Chita-Dist., Aichi 470-2341, Japan.

I. Sasaki. Advanced Materials Research Team, Materials and Geotechnical Engineering Research Group, Public Works Research Institute, Independent Administrative Institute, 1-6 Minamihara, Tsukuba, Ibaraki 305-8516, Japan.

S. Meiarashi. Materials and Geotechnical Engineering Research Group, Public Works Research Institute, Independent Administrative Institute, 1-6 Minamihara, Tsukuba, Ibaraki 305-8516, Japan.

Written discussion of this note is welcomed and will be received by the Editor until 30 April 2006.

${ }^{1}$ Corresponding author (e-mail: kyamaguc@tokaicarbon.co.jp). used for examining the thermal degradation during storage, mixing, and paving work, and the pressure aging vessel (PAV) test developed by the Strategic Highway Research Program (SHRP) is used for the in-service degradation. Besides heating and oxidation, the effects of UV radiation on asphalt pavement materials have been pointed out in numerous reports (Takemura 1962; Sakanoue and Kobayashi 1965; Meiarashi et al. 1999). However, there is no standardized test that allows quantitative evaluation of the photodegradation of asphalt materials. This paper describes a new method, "photodegradation test using pressed thin film samples", which was devised and applied to demonstrate the physical and chemical photodegradation behavior of asphalt materials.

\section{Method}

\section{Sample preparation and aging test}

The base asphalt was commercially available straight asphalt with the basic properties listed in Table 1. Samples were prepared through the procedure shown in Fig. 1.

\section{Thin film oven test}

Unaged samples were processed by the TFO test (Japan Road Association 1988), where $50 \pm 0.5 \mathrm{~g}$ asphalt, poured into the designated $140-\mathrm{mm}$-diameter plate, was exposed to air for $5 \mathrm{~h}$ at a temperature of $163{ }^{\circ} \mathrm{C}$. 
Table 1. Properties of the base asphalt binder.

\begin{tabular}{|c|c|c|c|c|c|}
\hline Properties & $\begin{array}{l}\text { Penetration at } 25^{\circ} \mathrm{C} \\
(1 / 10 \mathrm{~mm})\end{array}$ & $\begin{array}{l}\text { Softening } \\
\text { point }{ }^{\circ} \mathrm{C}\end{array}$ & $\begin{array}{l}\text { Viscosity at } 135 \\
{ }^{\circ} \mathrm{C}(\mathrm{mPa} \cdot \mathrm{s})\end{array}$ & $\begin{array}{l}\text { Density at } 15{ }^{\circ} \mathrm{C} \\
\left(\mathrm{g} / \mathrm{cm}^{3}\right)\end{array}$ & Flash point ${ }^{\circ} \mathrm{C}$ \\
\hline & 90 & 46 & 365 & 1.033 & 348 \\
\hline $\begin{array}{l}\text { Test } \\
\text { specification }\end{array}$ & JIS-K2207 6.3 & $\begin{array}{l}\text { JIS-K2207 } 6.4 \\
\text { R\&B }\end{array}$ & $\begin{array}{l}\text { JIS-K2207 } 6.14 \\
\text { Cannon-Fenske }\end{array}$ & $\begin{array}{l}\text { JIS-K2207 } 6.12 \\
\text { Hubbard bottle }\end{array}$ & JIS-K2265 COC \\
\hline
\end{tabular}

Fig. 1. Procedure for sample preparation.

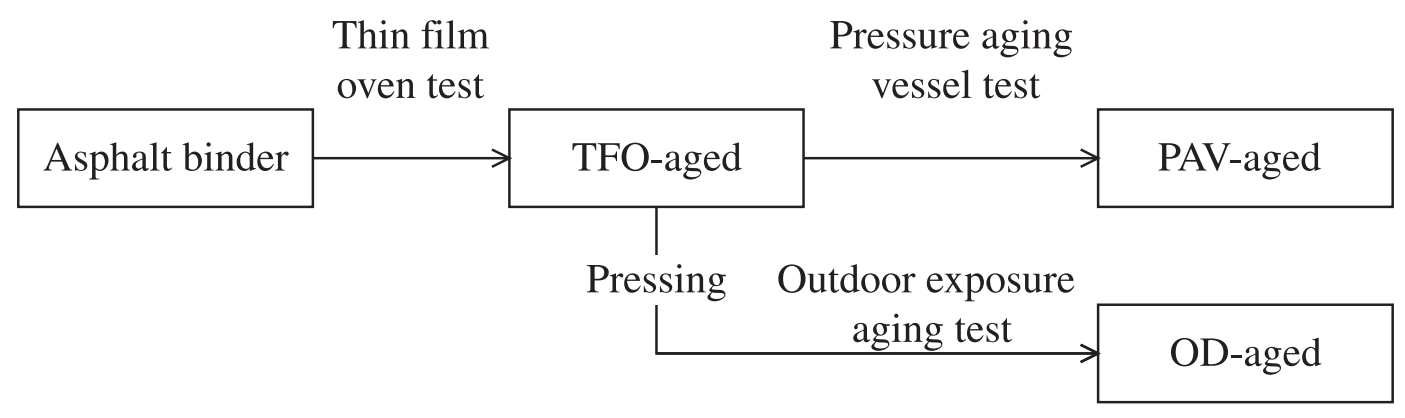

\section{Pressure aging vessel test}

The TFO-aged samples were subsequently processed by the PAV test (Harrigan et al. 1994), where the 140-mmdiameter plate was placed in high-pressure air of $2.1 \pm$ $0.1 \mathrm{MPa}$ for $20 \mathrm{~h}$ at a temperature of $100{ }^{\circ} \mathrm{C}$.

\section{Outdoor exposure aging test}

Photodegradation decreases with increasing depth from the surface of the asphalt layer; that is, the deeper the depth, the smaller the degradation. Therefore, quantitative understanding of the photodegradation behavior requires thinner specimens. The heating extension method and diluting process with organic solvent have been attempted to prepare thinner specimens, but there is a probability that heat degradation and (or) sample separation might occur due to the difference in relative density. In particular, it takes longer to completely remove the solvent from the samples. These problems made it difficult to evaluate the photodegradation behavior quickly and accurately.

To solve these problems a photodegradation test using pressed thin film samples was devised. An asphalt sample, which was sandwiched between poly-tetra-fluoro-ethylene (PTFE) sheets, was pressed into a thin film and exposed to light after peeling off the sheet on one side. Sample appearance before and after pressing is shown in Fig. 2. This method has the advantages of being able to eliminate the effect of heat degradation, to obtain a thin film sample with uniform thickness easily and quickly, and to collect the sample without difficulty after the test. For this experiment, $1.5 \mathrm{~g}$ of TFO-aged samples were prepared by pressing into $135 \mathrm{~mm} \phi, 100 \mu \mathrm{m}$ thickness sheets under the temperature of $60{ }^{\circ} \mathrm{C}$.

The outdoor exposure aging (OD) test was conducted in Tsukuba City located in Ibaraki Prefecture, Japan. Specimens were placed outside for 1 or 2 months facing south at a $5^{\circ}$ angle. A glass plate having UV transmittance of $60 \%$ in the $300-400 \mathrm{~nm}$ region was set with a $5 \mathrm{~mm}$ clearance above the specimen to prevent contamination from dirt and water that would damage the samples. The test conditions are shown in Table 2. As the maximum surface temperature of
Fig. 2. Sample appearance before and after pressing process.

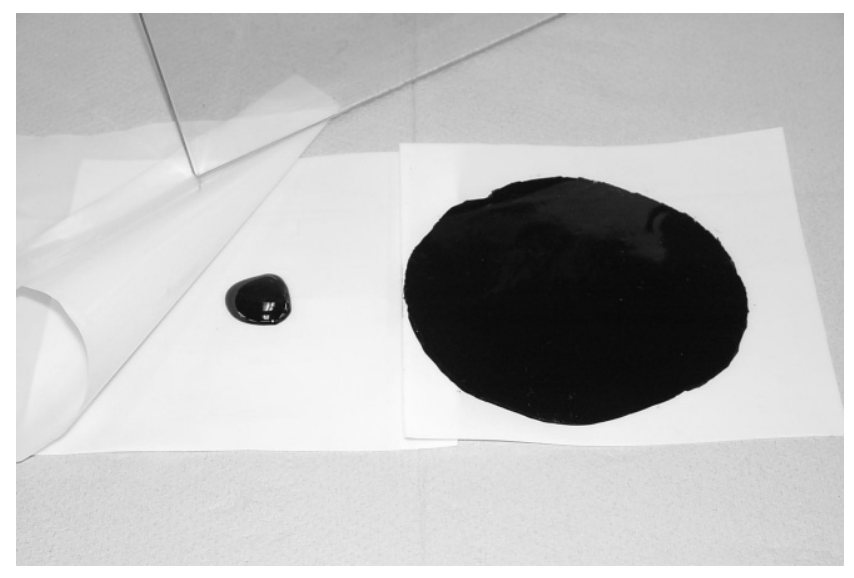

the specimens was around $45{ }^{\circ} \mathrm{C}$, the main degradation factor would be light instead of heat. The net UV dose was obtained by multiplying the actual UV dose with $60 \%$, which was the UV transmission of the glass plate.

\section{Test items}

\section{Dynamic shear rheometer test}

Dynamic viscoelastic properties (Harrigan et al. 1994) were examined using a dynamic shear rheometer (DSR), Rheometrix RAA (Rheometrix Scientific Inc.). The test temperature was controlled at $20^{\circ} \mathrm{C}$, because performance degradation occurs especially in the low temperature region as the degradation of asphalt material progresses. Measurements were performed at a frequency of $10 \mathrm{rad} / \mathrm{s}$, and a parallel plate $8 \mathrm{~mm}$ in diameter was used with a gap of $2 \mathrm{~mm}$. The indicator for the degree of degradation was selected as $\left|G^{*}\right| \sin \delta$, where $G^{*}$ is the dynamic complex modulus and $\delta$ is the phase angle between stress and strain.

\section{Fourier transform infrared spectroscopy}

Fourier transform infrared (FTIR) spectroscopy was applied to investigate the behavior of oxygen-containing func- 
Table 2. Conditions of the outdoor exposure aging test.

\begin{tabular}{llll}
\hline Items & OD-aged for 1 month & OD-aged for 2 months & Remarks \\
\hline Net UV dose $\left(\mathrm{MJ} / \mathrm{m}^{2}\right)$ & 4.6 & 10.6 & At the wavelength range of 300-400 nm \\
Max. UV intensity $\left(\mathrm{W} / \mathrm{m}^{2}\right)$ & 16.1 & 19.7 & Maximum/minimum \\
Surface temperature $\left({ }^{\circ} \mathrm{C}\right)$ & $43.5 /-7.6$ & $46.3 /-8.7$ & \\
\hline
\end{tabular}

tional groups, or carbonyl groups, which is an indication of oxidative degradation of asphalt materials (Tanaka et al. 1991). Spectra were recorded on a FTIR spectrometer, Spectrum One (Perkin Elmer, Inc.). A chloroform solution of $0.03 \mathrm{~g} / \mathrm{cm}^{3}$ was placed in a $\mathrm{KBr}$ liquid cell with a $0.1 \mathrm{~mm}$ spacer. The evaluation used the carbonyl index (CI) shown in eq. [1] because the transmittance of infrared light is affected by the degradation. The index is the absorbance ratio between the bands around 1600 and $1700 \mathrm{~cm}^{-1}$. The former band is caused by stretching vibration of the $\mathrm{C}=\mathrm{C}$ bond and is independent of degradation. This band was used as an internal reference. The latter is caused by stretching vibration of the $\mathrm{C}=\mathrm{O}$ bond. The background range was set at 1825 to $550 \mathrm{~cm}^{-1}$.

[1] $\mathrm{CI}=\log \left(\mathrm{I}_{01} / \mathrm{I}_{1}\right) / \log \left(\mathrm{I}_{02} / \mathrm{I}_{2}\right)$

where $I_{1}$ and $I_{2}$ are the transmittances of the bands around 1700 and $1600 \mathrm{~cm}^{-1}$, and $I_{01}$ and $I_{02}$ are the background transmittances, respectively.

\section{Results and discussion}

\section{Severity of photodegradation by outdoor exposure}

\section{Behavior of dynamic rheological properties}

Figure 3 shows the changes of $\left|G^{*}\right| \sin \delta$ at $20{ }^{\circ} \mathrm{C}$ for samples that were TFO-aged, PAV-aged, and OD-aged for 1 and 2 months. These are representative values of three specimens. Although the conditions of the PAV test are much more severe in temperature and ambient pressure, increase in $\left|G^{*}\right| \sin \delta$ by the OD test for a month exceeds the values for PAV test. As for the sample appearance after the OD test, numerous cracks had started and part of the aged surface was powdery and exhausted. In the surface layer (about 100 $\mu \mathrm{m}$ thickness) closer to light, the changes to viscoelastic properties by photodegradation was more enhanced after 1 to 2 months of OD test as compared with the PAV test, which is designed to simulate the degradation of the binder in asphalt pavement during about 5 to 10 years in service.

\section{Behavior of oxygen-containing functional groups}

Following the study on the physical photodegradation behavior, FTIR analysis was performed to investigate the chemical properties of the specimens. The CI, indicating oxidation, is shown in Fig. 4. As indicated by Sakanoue and Kobayashi (1965), photodegradation seems to be an oxidation reaction. The increase in CI was more by OD test for one month as compared with the PAV test. This result is consistent with the dynamic rheological measurement; that is, the increase in $\left|G^{*}\right| \sin \delta$ by OD test exceeded that by the PAV test.
Fig. 3. Comparison of severity between the OD test and the PAV test by DSR.

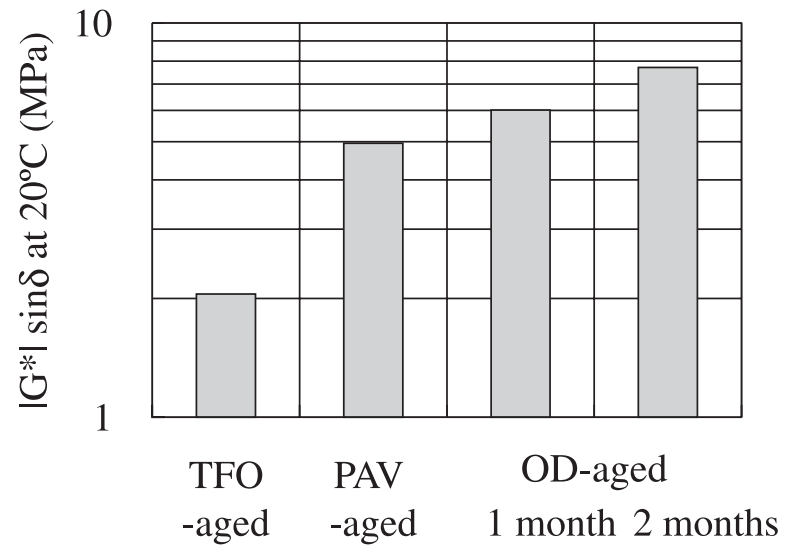

Fig. 4. Comparison of CI between the OD test and the PAV test by FTIR.

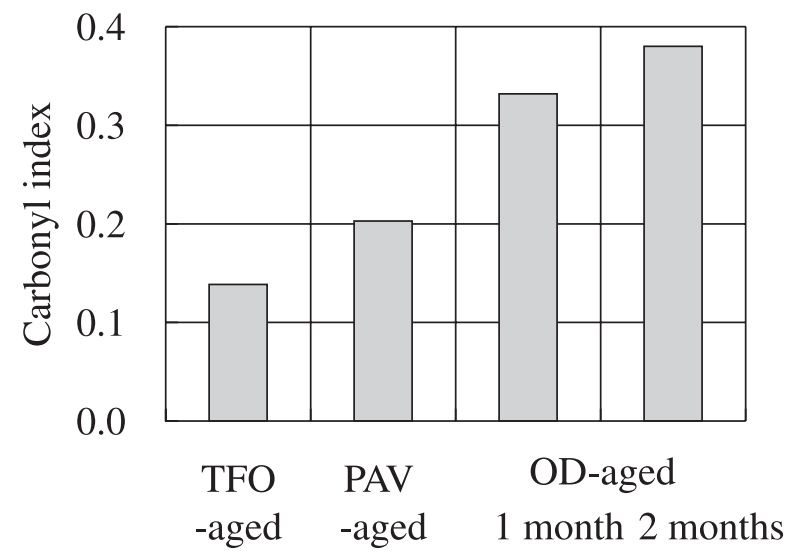

\section{Future tasks of photodegradation test using pressed thin film samples}

This test method will contribute in facilitating the study of the photodegradation mechanism on asphalt materials. However, the effects of film thickness on photodegradation should be examined because the effect of light is most severe at the surface and decreases with increasing depth. Also, more long-term examination for various binders must be carried out to establish this test method.

\section{Conclusions}

A new method, photodegradation test using pressed thin film samples, was developed and the photodegradation behavior of commercially available straight asphalt was investigated. Although photodegradation caused by outdoor exposure is limited to near the surface, the results confirmed 
that the degree of degradation during 1 to 2 months is more severe than that by the PAV test, which is designed to simulate the degradation that occurs in asphalt pavement over 5 to 10 years of service.

\section{Acknowledgements}

The authors wish to thank Dr. Akihiro Moriyoshi, Professor of Hokkaido University for his constructive review of the paper, and Dr. Itaru Nishizaki for his advice on the weathering test method and apparatus.

\section{References}

Harrigan, E.T., Leahy, R.B., and Youtcheff, J.S. 1994. The Superpave mix design system manual of specifications, test meth- ods, and practices. Strategic Highway Research Program, National Research Council (U.S.), Washington, D.C. SHRP-A-379

Japan Road Association. 1988. Manual for test method of pavement. Maruzen, Co., Ltd., Tokyo.

Meiarashi, S., Sasaki, I., and Osaka, S. 1999. The effect of ultraviolet irradiation on asphalt aging. Proceedings of the 23rd Japan Road Conference, Japan Road Association, Tokyo. pp. 482-483.

Sakanoue, S., and Kobayashi, H. 1965. Degradation of petroleum asphalt by ultraviolet irradiation. Sekiyu Gakkaishi (Journal of the Japan Petroleum Institute), 8(10): 44-50.

Takemura, K. 1962. Study of the aging of asphalt binders, part 1. Civil Engineering Research Institute of Hokkaido. Monthly Report no.114, pp. 1-7.

Tanaka, K., Suzuki, I., and Kajitani, I. 1991. Thermal degradation of asphalt binder for pavement. Institute of Civil Engineering of Tokyo Metropolitan Government, Tokyo. Annual Report, pp. 177-184. 